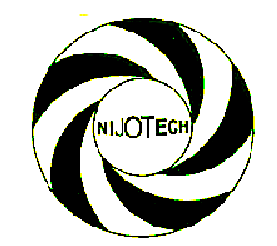

Nigerian Journal of Technology (NIJOTECH)

Vol. 33. No. 2, July 2014, pp. 268 - 274

Copyright@ Faculty of Engineering,

University of Nigeria, Nsukka, ISSN: 111 15-8443

www.nijotech.com

http://dx.doi.org/10.4314/njt.v33i3.4

\title{
KINEMATICS AND DYNAMIC EVALUATION OF THE SCREW CONVEYOR OF A CASSAVA CENTRIFUGE DEWATERING MACHINE
}

\author{
C. H. Kadurumba ${ }^{1, *}$ and S.0. Enibe ${ }^{2}$ \\ 1 National Root Crops ResEarch InSTItUTE, UmUdike, Abia State. NIGERIA. \\ 2 DePARTMENT OF MEChaniCAL ENGINEERING, UnivERSity OF NigERIA NSUKKA, NIGERIA. \\ Email addresses: ${ }^{1}$ kaduruchuma@yahoo.com, 2 enibesam@yahoo.com
}

\begin{abstract}
This paper presents the volumetric performance of a horizontal enclosed screw conveyor with reference to the influence of vortex motion. Vortex motion is as a result of internal friction, friction between the granular material and surface of the helical blade, and the variable helix angle of the helical flight from the outer periphery of the blade to the shaft. The vortex motion and the degree of fill, govern the volumetric efficiency and the volumetric throughput. An analysis of the vortex motion in a horizontal screw conveyor of a Cassava Centrifuge Dewatering Machine is presented. It is shown that the vortex motion is characterised by the tangential component of the absolute grain velocity being constant with the radial position of a point on the blade. On this basis, an expression for the volumetric efficiency is derived. The volumetric throughput can then be predicted. The study also showed the results of an experimental screw conveyor where the analytical predictions correlate closely to the measured results.
\end{abstract}

Keywords: screw conveyors, vortex motion, friction, cassava centrifuge, screw clearance, volumetric throughput, volumetric efficiency

\section{INTRODUCTION}

Screw conveyors are conveying devices used for relatively free flowing bulk solids. Their mechanics of conveying materials are complex. Because of this complexity, designers rely heavily on the empirical performance data of the screw conveyors. Roberts and Willis [11] and Rehkugler and Boyd [10] carried out detailed studies of the performance of screw conveyors. They used dimensional analysis and dynamic similarity to predict the performance of geometrically similar screw conveyors conveying grains. Also Rademacher [9] carried out a work on enclosed vertical screw conveyor performance. The design of the screw conveyor used in the centrifuge requires a detailed consideration of the geometry of the screw and the properties of the bulk material. In this study the theory developed by Roberts [12] was used to predict the volumetric performance of screw conveyor geometry of the centrifuge. An analytical model to predict the vortex motion, volumetric efficiency and volumetric throughput of the enclosed screw conveyor is presented. The relevant details of the screw conveyor are shown in Figure 1. The power driven screw flight is supported in bearings and revolves in a rotary filter basket. Practical limitations require a liberal clearance between the flight and the casing (filter basket) and this has been shown to be beneficial rather than detrimental to performance. The screw flight is allowed to project beyond the casing at a lower or intake end, this projection is referred to as the choke.

From Figure 1, the volumetric efficiency is limited by the degree of fill of the conveyor and the vortex or rotary motion of the material as it is transported by the screw. At higher rotational speed of the conveyor and reduced rotational speed of the bulk material, the screw conveyor becomes more efficient in conveying the material. However a decrease in fullness of the conveyor is usually accompanied by higher operating speeds.

Many equipment has been developed for the processing of cassava into various forms. These equipment include peeling machines $[6,7,8]$, cassava 
graters [1,3, 4] and dewatering machines [5]. In order to produce dried cassava mash, there is need to optimize the variables of the cassava centrifuge dewatering machine such as the screw conveyor.

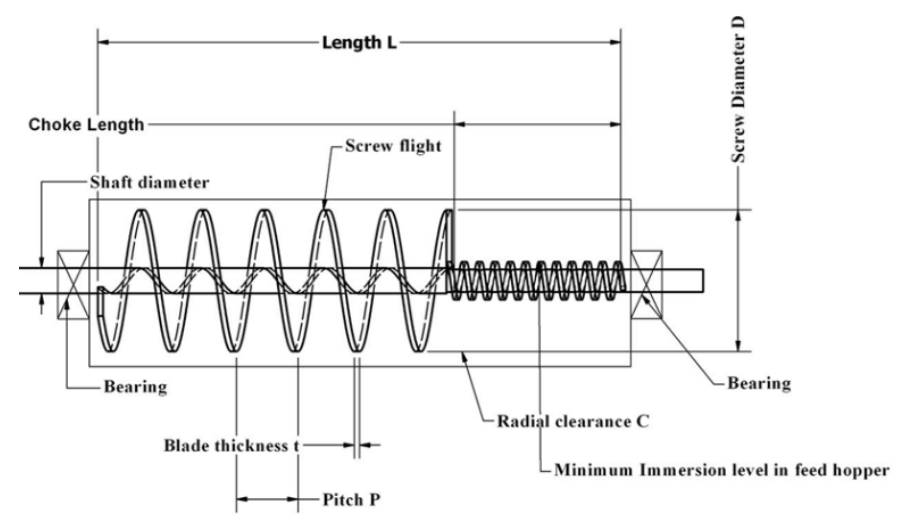

Figure 1: Enclosed screw conveyor with angle of elevation and height of lift equal to zero

\section{MATERIALS AND METHODS}

\subsection{Screw Conveyor Throughput}

The throughput of the screw conveyor was determined based on its volumetric throughput. Roberts [7] showed that the volumetric throughput may be expressed as;

$Q=\Gamma \omega \mathrm{D}^{3} \eta_{\mathrm{v}}$

Where;

$\Gamma=\frac{1}{8}\left[\left(1+2 \frac{\mathrm{C}}{\mathrm{D}}\right)^{2}-\left(\frac{\mathrm{D}_{\mathrm{i}}}{\mathrm{D}}\right)^{2}\right]\left[\frac{\mathrm{P}}{\mathrm{D}}-\frac{\mathrm{t}_{\mathrm{s}}}{\mathrm{D}}\right]$

$\eta_{v}$ is the volumetric efficiency, $D$ is the screw diameter $(0.16 \mathrm{~m}), \mathrm{D}_{\mathrm{i}}$ is the Core or shaft diameter $(0.05 \mathrm{~m}), \mathrm{P}$ is the Screw Pitch $(0.15 \mathrm{~m}), \omega$ is the Angular velocity of screw $(87.89 \mathrm{rad} / \mathrm{sec}), \mathrm{C}$ is the radial clearance $(0.005 \mathrm{~m}), \mathrm{t}_{\mathrm{s}}$ is the thickness of screw blade $(0.005 \mathrm{~m})$. Substituting, we have $\Gamma$ is the non dimensional screw geometry factor (0.116815). Using this in equation (1) a volumetric throughput of $4.09 \mathrm{~m}^{3} / \mathrm{s}$ was obtained. The data used in this study are the experimental results obtained by Kadurumba [2] using a Cassava Centrifuge Dewatering Machine.

The radial clearance $\mathrm{C}$ of the screw conveyor was chosen to be at least 1.5 times larger than the maximum particle size in order to prevent jamming of particles in the clearance space leading to particle attrition and increased energy loss. Also research has shown that the throughput of an enclosed screw conveyor is influenced by the rotational or vortex motion of the bulk material during transportation and degree of fill or fullness of the screw $[11,12]$. As the rotational speed of the conveyor increases, the rotational or vortex motion decreases (up to a limiting value) making for a more efficient conveying action. But in the centrifuge the conveying action is low because of the increased vortex motion of the mash. However, when gravity feed system into the screw intake is employed; the feed rate cannot match the potential conveying capacity. This causes a reduction in fullness. The net result is for the throughput of the screw conveyor to reach a limiting value as shown in Figure 2.

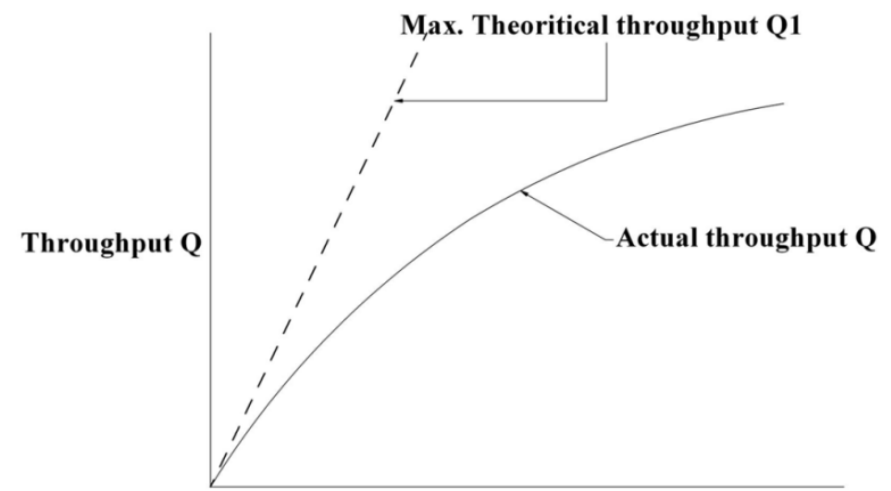

Rotational speed of conveyor $\omega$

Figure 2: Throughput of an enclosed screw conveyor

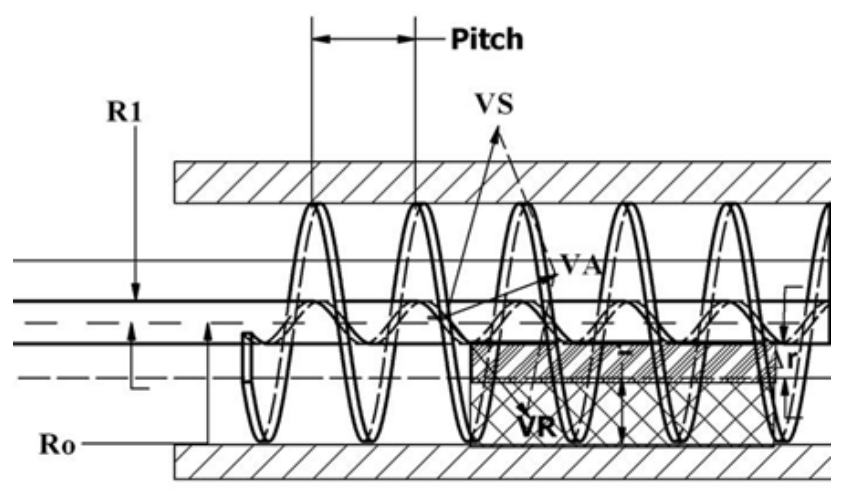

Figure 3: Mechanism of conveying action in a screw conveyor

Roberts and Willis [11] showed that, the volumetric efficiency of a screw conveyor is the product of two components namely: Rotational or vortex efficiency and fullness efficiency. Mathematically, it is represented as

$\eta_{\mathrm{V}}=\eta_{\mathrm{VR}} \eta_{\mathrm{f}}$

Where, $\eta_{V R}$ is the Rotational or Vortex efficiency, $\eta_{\mathrm{f}}$ is the fullness efficiency.

$\eta_{\mathrm{f}}=\frac{\mathrm{h}_{\mathrm{av}}}{\mathrm{P}}$

$h_{a v}$ is the average height of material on the screw surface

\section{KINEMATIC ANALYSIS OF THE SCREW CONVEYOR ACTION}

The conveying action of the screw conveyor is shown in Figure 3. As the screw rotates a particle of bulk solid (cassava mash) moves in a helical path of opposite hand to that of the screw. Referring to the 
velocity diagram shown in Figure $3, V_{s}$ is the tangential velocity of the screw at the radius considered. $V_{R}$ is the relative velocity of the particle with respect to the screw surface. $V_{A}$ is the absolute velocity of the particle. The angle $\lambda$ defines the direction of the absolute velocity and thus, the helix angle of the path followed by the particles at the radius considered. The limited feed rate into the screw intake causes the conveyor to run less than $100 \%$ full. The fullness decreases with increase in speed and it is indicated by the variation in radius ' $r$ ' relative to the screw pitch ' $\mathrm{P}$ ' as shown in Figure 3. The velocity diagram shown in Figure 3 is further elaborated in Figure 4 . The screw velocity at the radius ' $r$ ' is defined by:

$\mathrm{V}_{\mathrm{S}}=\mathrm{r} \omega$

where $\omega=\frac{\pi \mathrm{n}}{30}$ is the angular velocity of the screw and $\mathrm{n}$ is the rotational speed in rads/sec.

$\mathrm{V}_{\mathrm{LT}}$ is the maximum theoretical conveying velocity in $(\mathrm{m} / \mathrm{s}), \mathrm{t}_{\mathrm{s}}$ is the thickness of screw blade in meters. The helix angle ' $\alpha$ ' of the screw at the radius ' $r$ ' is given by

$\alpha=\tan ^{-1} \frac{P}{2 \pi r}$

where $P$ is the pitch $(0.15 \mathrm{~m})$ and $r=0.03 \mathrm{~m}$. Hence from equations (5) and (6) the velocity and helix angle of the screw was obtained as $0.5595 \mathrm{~m} / \mathrm{s}$ and $38.5^{\circ}$ respectively.

The helix angle of the screw increases from $\alpha_{0}$ at the outer periphery of the screw to $\alpha_{1}$ at the core or shaft. Hence the helix angle $\lambda$ of the path of particles of bulk material decreases from $\lambda_{0}$ at the outer periphery to $\lambda_{1}$ at the core. The helix angle is such that

$\lambda \leq\left[\left(90^{\circ}-\left(\alpha+\phi_{S}\right)\right]\right.$

$\Phi_{\mathrm{s}}\left(20^{\circ}\right)$ is the friction angle for bulk solid (cassava mash) on screw surface. The helix angle of the particle was obtained as $31.5^{\circ}$ after substitution in equation (7). As a result of the vortex motion established within the bulk material, internal shear between concentric layers occurs. In the case of free flowing materials, the internal shear is readily generated. But this is not the case with cohesive and fibre-like materials which do not convey well in steeply inclined auger conveyors. The motion of bulk particles relative to the screw surface is defined by the relative velocity $V_{R}$ and it is given by

$\mathrm{V}_{\mathrm{R}}=\frac{\mathrm{V}_{\mathrm{S}} \sin \lambda}{\sin (\alpha+\lambda)}$

A value of $0.311 \mathrm{~m} / \mathrm{s}$ (eqn.8) was obtained as the relative velocity of the particle. The magnitude of the relative velocity depends primarily on the frictional resistive force provided by the conveyor casing (filter basket). This force depends mainly on the casing friction coefficient and the normal force on the inner casing surface as imposed by the centrifugal force of the rotating bulk material. The absolute velocity $V_{A}$ is the vector addition of $V_{S}$ and $V_{R}$ as shown in equation (9).

$\overline{V_{A}}=\overline{V_{S}}+\overline{V_{R}}$

The magnitude of the absolute velocity is given by;

$V_{A}=\frac{V_{S} \sin \alpha}{\sin (\alpha+\lambda)}$

From eqn. (10) $0.3707 \mathrm{~m} / \mathrm{s}$ was obtained as the magnitude of the absolute velocity of the particle. The absolute velocity $\mathrm{V}_{\mathrm{A}}$ has two components and this include;

(1) The useful conveying component $\mathrm{V}_{\mathrm{L}}$

(2) The wasteful rotational component $V_{T}$ $\mathrm{V}_{\mathrm{L}}$ and $\mathrm{V}_{\mathrm{T}}$ respectively are given by this relation;

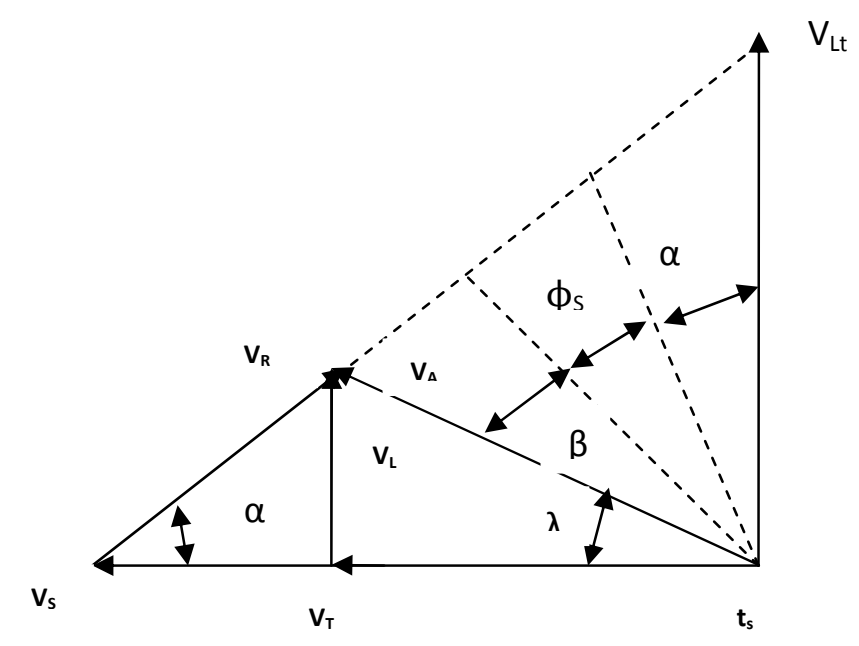

Figure 4: Velocity diagram for cassava mash particle 
$V_{L}=V_{A} \sin \lambda$

$V_{T}=V_{A} \cos \lambda$

Thus,

$V_{T}=\frac{V_{S} \sin \alpha \cos \lambda}{\sin (\alpha+\lambda)}$

$V_{L}=\frac{V_{S} \sin \alpha \sin \lambda}{\sin (\alpha+\lambda)}$

Substituting in eqns. (11) and (12), the values of the useful conveying $\left(\mathrm{V}_{\mathrm{L}}\right)$ and wasteful rotational $\left(\mathrm{V}_{\mathrm{T}}\right)$ components of the conveyor were obtained as 0.1937 and $0.3161 \mathrm{~m} / \mathrm{s}$ respectively.

\section{DYNAMIC ANALYSIS OF CONVEYING ACTION}

The forces acting on a particle in a screw conveyor are shown in figure 5 . Also shown are the velocity components. The cassava mash particle at the outer periphery in contact with the rotary casing exerts a force $F_{N}$ against the casing. This is mainly as a result of the centrifugal pressure. The centrifugal pressure gives rise to the normal pressure $P_{n}$ acting at the casing. A frictional drag force $F_{D}=\mu_{c} F_{N}$ acts in a direction opposing the absolute velocity as shown in figure 5 .

At an arbitrary radius $r$, the forces on a particle are as shown in Figure 6 , where $\mu_{c}$ is the coefficient of friction for the mash particles on the casing surface. Due to internal shear, a drag force $F_{D}$ is assumed to act as indicated, where the internal friction coefficient $\mu_{\mathrm{g}}$ replaces the casing or boundary friction coefficient $\mu_{c}$. The force component $F_{R}$ is the resultant force due to sliding on the screw surface. Usually in a vertical screw conveyor arrangement, there is an axial force component $\left(\mathrm{F}_{\mathrm{A}}\right)$ due to particle weight of bulk material on the screw surface. But in the case of the horizontal screw conveyor under study, there is no weight component. As a result, only frictional drag exists. Hence $\mathrm{F}_{\mathrm{A}} \approx 0$ and $\mathrm{F}_{\mathrm{R}}=\mathrm{F}_{\mathrm{D}}$. The path of the particles is such that

$\lambda=90^{\circ}-\left(\alpha+\phi_{S}\right)$

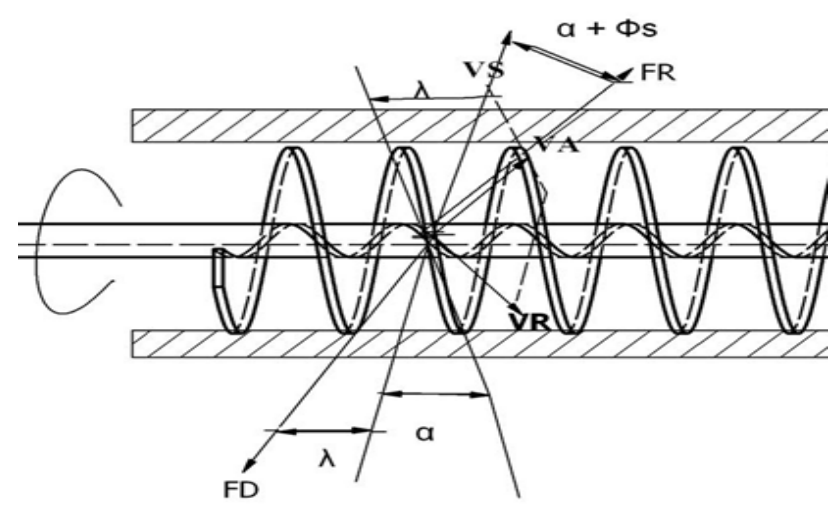

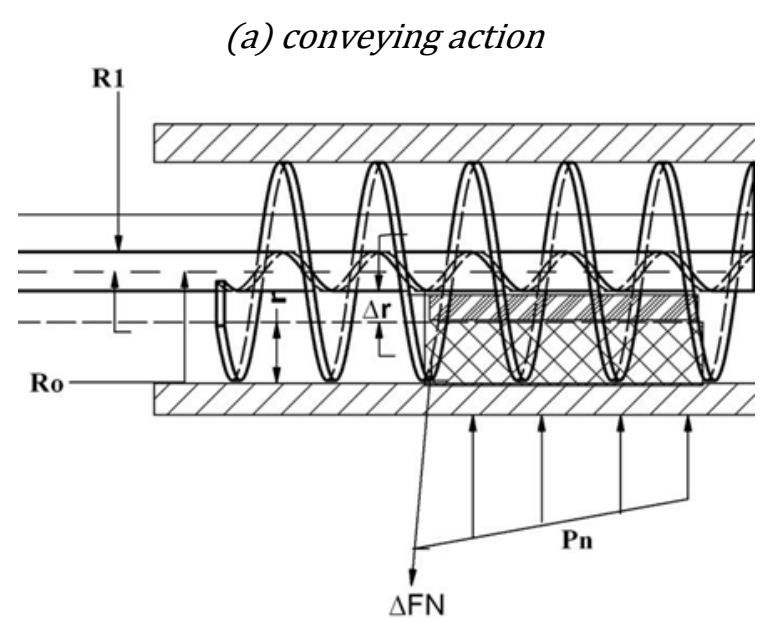

(b) View Showing Cut-Away Section

Figure 5: Forces acting in a horizontal conveyor

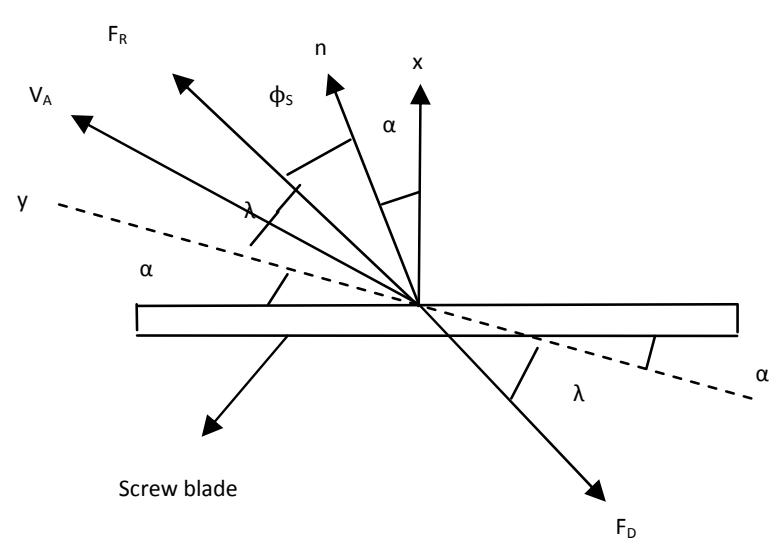

Figure 6: Forces acting on cassava mash particle in contact with screw surface

\section{STRESS FIELDS}

The normal pressure $P_{n}$ (Figure 6) at the casing surface is a Janssen type of distribution. Since shallow bed conditions exist on the screw blade, the pressure distribution may be assumed to be linear. Apart from gravitational influences, the stress field existing in the screw is very dependent on the speed of rotation.

\subsection{Low Speed of Rotation}

At low speeds of rotation, the stress field is assumed to be active with the major principal pressure acting almost vertical. In view of the motion of the bulk material and low bed depths, $\mathrm{h} \leq \mathrm{D}$, the vertical pressure may be assumed to be hydrostatic. This means that the pressure distribution is triangular. The pressure $P_{n}$ at the free surface is zero.

$\mathrm{P}_{\mathrm{V}}=\gamma \mathrm{h}$

where $\mathrm{P}_{\mathrm{V}}$ is the axial pressure $(\mathrm{Pa}), \mathrm{D}$ is the screw diameter $(M), \gamma$ is the bulk specific weight $\left(\mathrm{N} / \mathrm{m}^{3}\right), \rho$ 
is the bulk density, $\mathrm{h}$ is the height of bulk solid at radius considered and $\mathrm{K}_{\mathrm{j}}$ is the Pressure ratio.

Thus,

$\mathrm{P}_{\mathrm{V}}=\rho g h$

The lateral or normal pressure is given by

$\mathrm{P}_{\mathrm{n}}=\mathrm{K}_{\mathrm{j}} \mathrm{P}_{\mathrm{V}}$

$K_{j}=\frac{P_{n}}{P_{V}}$

Where $K_{j}=0.4$ to 1.0 , the higher values being more relevant at higher conveying speeds. In a horizontal screw arrangement the height (h) of the bulk material on motion is zero. Hence the normal pressure at the conveyor surface is zero.

\subsection{High Speeds of Rotation}

At high speeds where the centrifugal inertia effects dominate, the stress field switches to a passive state with the major principal pressure equal to the lateral or normal pressure acting in a horizontal direction. In this case the pressure distribution for $\mathrm{P}_{\mathrm{n}}$ is constant.

\subsection{Intermediate Speeds of Rotation}

In this situation the pressure distribution is a combination of the low and high speeds of rotation.

\section{FORCE COMPONENTS}

\subsection{Low Speed Operation}

By considering an annular segment of bulk solid of weight $\mathrm{W}(4.9 \mathrm{~N})$, at the active state of stress, the lateral normal force is given by

$\mathrm{N}_{\mathrm{A}}=\mathrm{K}_{\mathrm{S}} \mathrm{W}$

$\mathrm{N}_{\mathrm{A}}=\frac{2 \mathrm{~K}_{\mathrm{j}} \mathrm{PW}}{\mathrm{D}}$

where

$$
\mathrm{K}_{\mathrm{S}}=\frac{2 \mathrm{PK}_{\mathrm{J}}}{\mathrm{D}}
$$

In (20) to (22), $\mathrm{W}$ is the weight of the annular segment $(\mathrm{N}), \mathrm{N}_{\mathrm{A}}$ is the lateral force $(\mathrm{N}), \eta_{\mathrm{F}}=\frac{\mathrm{P}}{\mathrm{D}}$ is the fullness efficiency or pitch to diameter ratio, $\mathrm{D}$ is the screw diameter $(\mathrm{m}), \mathrm{K}_{\mathrm{J}}$ is the pressure ratio Eqn. (19), $P$ is the pitch of screw (m), $K_{s}$ is the pressure ratio Eqn. (22)

$\mathrm{K}_{\mathrm{J}}=0.6$ for the high speed conveyor was obtained from a standard table [2], a pitch of $0.15 \mathrm{~m}$ and a diameter of $0.16 \mathrm{~m}, \mathrm{~K}_{\mathrm{s}}=\mathrm{K}_{\mathrm{J}}=$ pressure ratio

$$
\begin{gathered}
\mathrm{K}_{\mathrm{S}}=\frac{2 \times 0.15 \times 0.6}{0.16}=1.125 \\
\mathrm{~N}_{\mathrm{A}}=0.5 \times 9.81 \times 0.2475=5.52 \mathrm{~N}
\end{gathered}
$$

Thus a lateral normal force (NA) of $5.52 \mathrm{~N}$ was obtained.

\subsection{Centrifugal Pressure}

At any radius $r$, the absolute velocity of the particles is $\mathrm{V}_{\mathrm{A}}$ and the particles move in a curved path of radius of curvature equal to the maximum radius of curvature of an ellipse. This is illustrated in figure 6 . The radius of curvature $R_{C}$ of the equivalent ellipse is $\mathrm{R}_{\mathrm{C}}=\frac{\mathrm{a}^{2}}{\mathrm{~b}}$ where, $\mathrm{a}$ is the semi major axis of the ellipse and equals; $a=\frac{r}{\cos \lambda}, \mathrm{b}$ is the semi minor axis, $\mathrm{b}=\mathrm{r}$ $\mathrm{R}_{\mathrm{C}}=\frac{\mathrm{r}}{\cos ^{2} \lambda}$

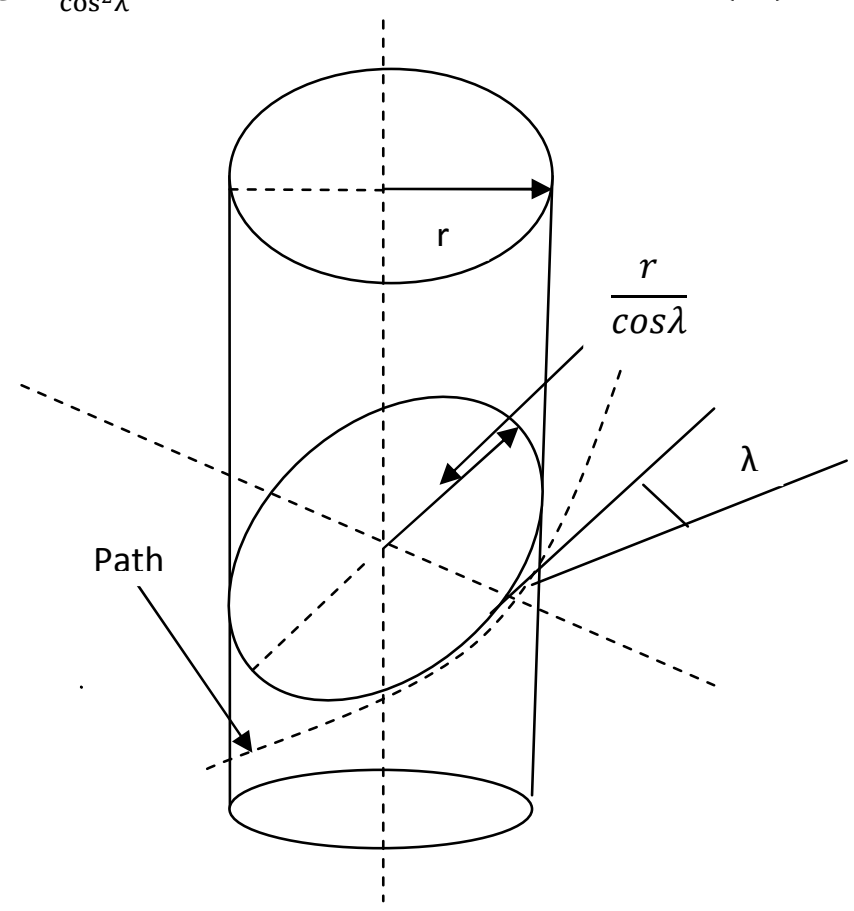

Figure 6: Ellipse defining curvature of particle path at radius considered.

From equation (23) the radius of curvature $\left(R_{C}\right)$ was obtained as $0.04 \mathrm{~m}$ at a radius $(\mathrm{r}=0.03 \mathrm{~m})$ and helix angle of particle $\left(\lambda=31.0^{\circ}\right)$. Considering an annular segment of bulk solid of weight $W$, then the centrifugal force $\mathrm{N}_{C}$ (Roberts, 1999) is given by

$\mathrm{N}_{\mathrm{C}}=\frac{\mathrm{WV_{ \textrm {A } } ^ { 2 }}}{\mathrm{R}_{\mathrm{C}} \mathrm{g}}$ or $\mathrm{N}_{\mathrm{C}}=\frac{\mathrm{WV}_{\mathrm{A}}^{2} \cos ^{2} \lambda}{\mathrm{rg}}$

From equation (12);

$V_{T}=V_{A} \cos \lambda$

Hence,

$\mathrm{N}_{\mathrm{C}}=\frac{\mathrm{wV}_{\mathrm{T}}^{2}}{\mathrm{rg}}$

Such that,

$\mathrm{V}_{\mathrm{T}}=\left[\frac{\tan \alpha}{\tan \alpha+\tan \lambda}\right] \mathrm{V}_{\mathrm{S}}$

Since $V_{S}=r \omega$, then equation (26) becomes

$N_{C}=W\left[\frac{\tan \alpha}{\tan \alpha+\tan \lambda}\right]^{2} \frac{r \omega^{2}}{g}$

The general case involves a combination of $\mathrm{N}_{\mathrm{a}}$ and $\mathrm{N}_{\mathrm{c}}$ $N=N_{a}+N_{C}$

$N=W\left[K_{S}+\left[\frac{\tan \alpha}{\tan \alpha+\tan \lambda}\right]^{2} \frac{r \omega^{2}}{g}\right]$ 
where $\mathrm{N}$ is the total normal force on annulus $(\mathrm{N}), \mathrm{N}_{\mathrm{C}}$ is the centrifugal force due to annulus $(\mathrm{N}), \mathrm{N}_{\mathrm{a}}$ is the normal force on annulus $(\mathrm{N}), \mathrm{W}$ is the weight of annular segment $(4.905 \mathrm{~N}), \mathrm{K}_{\mathrm{S}}$ is the pressure ratio (1.125), $\mathrm{V}_{\mathrm{T}}$ is the rotating velocity component $(\mathrm{m} / \mathrm{s})$, $\mathrm{V}_{\mathrm{A}}$ is the absolute velocity $(\mathrm{m} / \mathrm{s})$. Substituting the values of helix angle of screw $\left(\mathrm{H}_{\mathrm{A}}=\alpha=39.0^{\circ}\right)$, helix angle of bulk material $\lambda=31.0^{\circ}$, radius of bulk material $=0.03 \mathrm{~m}$, acceleration due to gravity $=$ $9.81 \mathrm{~m} / \mathrm{s}^{2}$ and angular speed of screw conveyor as 87.89rad/s in eqn. (27).

$$
\begin{gathered}
N=4.905\left[1.125+\left[\frac{\tan 39}{\tan 39+\tan 31}\right]^{2} \frac{0.03 \times 87.89^{2}}{9.81}\right] \\
=115.89
\end{gathered}
$$

A total normal force of $155.89 \mathrm{~N}$ on annulus was obtained. Considering handling safety for processed food, stainless steel plate having a bulk density of $7728 \mathrm{~kg} / \mathrm{m}^{3}$ and $1026.15 \mathrm{~N}$ (Robert, 1999) was chosen for the spiral flight design. Hence, the cassava mash of bulk density $988.65 \mathrm{~kg} / \mathrm{m}^{3}$ to $1379.99 \mathrm{~kg} / \mathrm{m}^{3}$ used in the study [1] is within the stainless steel material range.

\section{VORTEX EFFICIENCY}

The vortex efficiency provides a measure of the volumetric throughput of a conveyor running $100 \%$ full. The vortex efficiency for the horizontal screw conveyor is given by [7] as:

$\eta_{\mathrm{VR}}=1-\frac{1+2 \pi \mu_{\mathrm{S}} \zeta_{\mathrm{av}}}{4 \pi^{2} \zeta_{\mathrm{av}}+1}$

where $\zeta=\frac{r}{\mathrm{P}}, \zeta_{0}=\frac{\mathrm{R}_{\mathrm{O}}}{\mathrm{P}}, \zeta_{1}=\frac{\mathrm{R}_{1}}{\mathrm{P}}, \zeta_{\mathrm{av}}=\frac{\left(\zeta_{0}+\zeta_{1}\right)}{2}, \zeta_{\mathrm{av}}$ is the average value of ratio of radius to pitch,$\zeta_{0}$ is the ratio of radius to pitch at outer screw radius; $\zeta_{1}$ is the ratio of radius to pitch at inner screw radius and $\eta_{F}$ is the fullness efficiency. Other variables are:

$\mu_{S}=$ friction coefficient at screw surface (0.15)

$\mathrm{R}_{\mathrm{o}}=$ screw radius at outer periphery $(0.08 \mathrm{~m})$

$\mathrm{R}_{1}=$ shaft radius $(0.025 \mathrm{~m})$

$\mathrm{P}=$ pitch of screw $(0.15 \mathrm{~m})$

$\zeta_{\mathrm{av}}=\frac{(0.533+0.166)}{2}=0.3496$

$\eta_{\mathrm{VR}}=1-\frac{1+2 \pi \times 0.15 \times 0.35}{4 \times 3.142^{2} \times 0.35^{2}+1}=1-0.06821=0.9318$

The coefficient of friction at the screw surface was

obtained from a standard table (Khurmi and Gupta, 2006). Using eqn. (31) the vortex efficiency was obtained as 0.9318 (93.18\%).

Absolute path of motion defined by helix angle of particle at outer periphery (Roberts, 1999) is given by

$\mathrm{N}_{\mathrm{S}}=\frac{\omega^{2} \mathrm{R}_{0}}{\mathrm{~g}}$
Where $\mathrm{N}_{\mathrm{S}}$ is the specific speed, $\mathrm{R}_{0}$ is the outer radius, $\mathrm{g}$ is the gravitational acceleration, and $\omega$ is the angular velocity

$$
\mathrm{N}_{\mathrm{S}}=\frac{87.89^{2} \times 0.08}{9.81}=62.99 \mathrm{rad} / \mathrm{s}
$$

From eqn. (32) the absolute path of motion was obtained as $62.99 \mathrm{rad} / \mathrm{s}$.

The volumetric throughput could then be predicted from equation (1) as;

$Q=0.1168 \times 87.89 \times 0.16^{3} \times 93.18=4.09 \mathrm{~m}^{3} / \mathrm{s}$

The volumetric efficiency could then be calculated from equation (3) as:

$$
\eta_{\mathrm{V}}=\eta_{\mathrm{VR}} \eta_{\mathrm{f}}=93.18 \% \times 1=93.18 \%
$$

The vortex efficiency of the machine and the volumetric efficiency of the machine is $93.18 \%$ since the screw conveyor is assumed to be running at full capacity. Finally the result from the design analysis of the screw conveyor showed that the calculated conveyor screw helix angle is $39^{\circ}$ and that of cassava bulk material is $31^{\circ}$. And this was seen to agree closely with the experimental result of $37^{\circ}$ helix angle and $80 \%$ volumetric efficiency of the Cassava Centrifuge Dewatering machine reported in [2] (See Table 1).

\section{RESULTS AND DISCUSSIONS}

The results of the developed models and optimization for the Cassava centrifuge according to the findings [1], Table 1 shows that the optimized volumetric efficiency of the product recovery is $80 \%$ which agree closely with the calculated the value of $93.07 \%$ (equation (3).

The optimization of the developed models was done using the response optimizer of MINITAB version 15 to ensure accuracy of the results. The developed models for the cassava centrifuge are given by the equations below:

$$
\begin{aligned}
\mathrm{X}_{1} & =\frac{\mathrm{D}^{3} \mathrm{~F}_{\mathrm{S}}}{\mathrm{Q}} \\
\mathrm{X}_{2} & =\frac{\mathrm{C}_{\mathrm{S}}}{\mathrm{F}_{\mathrm{S}}} \\
\mathrm{X}_{3} & =\mathrm{H}_{\mathrm{A}} \\
\mathrm{X}_{4} & =\mathrm{D}_{\mathrm{M}}
\end{aligned}
$$

Similarly, the output variables $Y_{i}$ are given by

$\mathrm{Y}_{1}=\mathrm{P}_{\mathrm{M}}$

$\mathrm{Y}_{2}=\mathrm{P}_{\mathrm{R}}$

$\mathrm{Y}_{3}=\mathrm{E}_{\mathrm{R}}$

where, $X_{1}$ is the dimensionless pool depth number, $X_{2}$ is the speed ratio, $X_{3}$ is the Helix angle (radians), $X_{4}$ is the dry matter content (\%), $\mathrm{Y}_{1}$ is the product moisture content (\%), $\mathrm{Y}_{2}$ is the product recovery (\%) and $Y_{3}$ is the effluent recovery (\%), Also the result 
from the design analysis of the screw conveyor showed that the calculated conveyor screw helix angle is $39^{\circ}$ and that of cassava bulk material is $31^{\circ}$ (equations 6 and 7). This value of $39^{\circ}$ is very close to the optimized value of $37^{\circ}$ (See Table 1 ).

Table 1: Results of the optimal values of the independent and dependent of cassava centrifuge.

\begin{tabular}{lll}
\hline $\begin{array}{l}\text { Serial } \\
\text { No }\end{array}$ & $\begin{array}{l}\text { Centrifuge variables } \\
\text { Independent variables }\end{array}$ & $\begin{array}{l}\text { Optimum } \\
\text { values }\end{array}$ \\
\hline 1 & Helix angle $\left({ }^{0}\right)$ & 37.0 \\
2 & Feed flow rate $\left(\mathrm{m}^{3} / \mathrm{s}\right)$ & 0.0001976 \\
3 & Dry matter content $(\%)$ & 34.1 \\
4 & Pool depth $(\mathrm{m})$ & 0.0254 \\
5 & Conveyor speed (rad/s) & 87.89 \\
6 & Filter basket speed $(\mathrm{rad} / \mathrm{s})$ & 169.02 \\
7 & Bulk density $\left(\mathrm{kg} / \mathrm{m}^{3}\right)$ & 1174.02 \\
\hline & Dependent variables & \\
1 & Product moisture content $\left(\mathrm{P}_{\mathrm{M}}\right)$ & $30.67 \%$ \\
2 & Product recovery $\left(\mathrm{P}_{\mathrm{R}}\right)$ & $80.0 \%$ \\
3 & Effluent stream recovery $\left(\mathrm{E}_{\mathrm{R}}\right)$ & $18.0 \%$ \\
\hline
\end{tabular}

\section{CONCLUSIONS}

The study shows that the design of screw conveyors requires a detailed consideration of the geometry of the screw and the properties of the bulk material. The performance of screw conveyors has been based on experimental studies using dimensional analysis and dynamic similarity to predict the performance of geometrically screw conveyors only. The analysis and methodology presented in this study provide a general basis for screw conveyor performance prediction. The volumetric performance of enclosed screw conveyors with particular reference to the influence of vortex motion has been investigated. Vortex motion arises as a result of internal friction, friction between the granular material and surface of the helical blade, and the variable helix angle of the helical flight from the outer periphery of the blade to the shaft. The vortex motion, together with the degree of fill, governs the volumetric efficiency and the volumetric throughput. An analysis of the vortex motion in a horizontal auger conveyor has been presented. Because of the dominance of the centrifugal pressure due to the motion of the screw, a passive state of stress is generated within the bulk granular material. It is shown the vortex motion is characterised by the tangential component of the absolute grain velocity being substantially constant with the radial position of a point on the blade. On this basis, an expression for the volumetric efficiency is derived. The volumetric throughput can then be predicted.

\section{REFERENCES}

[1] Akinyemi, J.0, and Akinlua, O. Design, Construction and Testing of Cassava Grater. International Journal of Tropical Agriculture, vol. 17, 1999, pp103-108.

[2] Kadurumba C.H. (2014) Performance Evaluation of Centrifuge Cassava Dewatering Machine . An unpublished Ph.D thesis submitted to the Department of Mechanical Engineering, University of Nigeria Nsukka.

[3] Khurmi R.S. and Gupta J.K. (2006) A Textbook of Machine Design. Eurasia Publishing House Ltd. Ram8 Nagar, New Delhi-pp11-55.

[4] Odigbo. E.U.(1984). A Manually Operated Cassava Grating Machine. Nigerian Journal of Technology, Vol. 8, No.1, pp 15-18.

[5] Odigbo. E.U. (2011). Cassava Production, Processing and Utilization. In [12], 11th International Conference and 32nd Annual General Meeting of the Nigerian Institution of Agricultural Engineers Ilorin Nigerian, October.

[6] Olunkule, O.J. and Ademosun, O.C.(2006). Development of Double Action Self-Fed Cassava Peeling Machine. Journal of Food, Agriculture and Environment, vol. 4, pp. 3-4.

[7] Olunkule, O.J. and Atere, O.A.(2009). Development in Cassava Peeling Mechanization. International Conference of the Nigerian Institution of Agricultural Engineers/West Africa society of Agricultural Engineers, Ile-Ife Nigeria.

[8] Olunkule, O.J. and Oguntunde, O.(2008). Analysis of Peeling Pattern in An Automated Cassava Peeling System. Nigeria Journal of Technological Development, Vol 6, no. 1 and 2, pp 41-52.

[9] Rademacher F.J.C. (1979) VDI. Forschungsheftp.592

[10] Rehkugler G.E and Boyd (1962) Dimensional Analysis of Auger conveyor Operation. Transactions. American Society of Agricultural Engineers .5(1) pp.98-102

[11] Roberts A.W. and Willis A.H.(1962) Performance of Grain Augers. Proceedings of Institution of Mechanical Engineers. 175, pp165.

[12] Roberts A.W. (1964) Performance of Grain Augers. Proceedings of Institution of Mechanical Engineers . 178, pp293. 